\title{
Conceptual Design of a Next Generation, 150 Passenger Commercial Transport
}

\author{
Ryan Halper, Kevin Lane, Dustin Marschik, Brett Morham and John Pham ${ }^{1}$, Rob McDonald ${ }^{2}$, and Bruce Wright ${ }^{3}$ \\ Aerospace Engineering, California Polytechnic State University, San Luis Obispo, CA, 93407
}

In response to the 2008-2009 AIAA Undergraduate Team Design Competition's Request for Proposals for an advanced, environmentally compatible, 150 seat commercial transport; Jackson West has designed the Sparrow JS-3. The Sparrow represents the next step in the evolution of commercial aviation. Scheduled to enter service in 2018, The Sparrow will compete directly with the Boeing 737 and Airbus A320. Its improvements in fuel consumption and operating cost, as well as its reduced environmental impact, make The Sparrow the ideal solution to this RFP.

\section{Introduction}

When studying the RFP it became clear that emphasis is placed on certain aspects of the design. This warranted a quantified prioritization of the metrics against which design decisions were evaluated. Table 1 contains the result of this process. Because fuel burn is the most heavily weighted criterion, the Breguet range equation, as seen in Figure 1, was often used as a calibration to see how design decisions affect fuel burn.

Table 1: Design Requirement Prioritization

\begin{tabular}{|l|l|}
\hline Figure of Merit & Relative Importance \\
\hline Reduced Fuel Burn & $60 \%$ \\
\hline Reduced Community Noise & $16 \%$ \\
\hline Increased Fleet Productivity & $14 \%$ \\
\hline Decreased Maintenance Cost & $8 \%$ \\
\hline Improved Passenger Comfort & $2 \%$ \\
\hline
\end{tabular}

$$
\begin{gathered}
R=\frac{V L}{D} \frac{1}{T S F C} \ln \left(\frac{W_{f}}{W_{i}}\right) \\
\text { Aero Propulsion Weights } \\
\text { Figure 1: Breguet Range Equation }
\end{gathered}
$$

\section{Initial Sizing}

One of the first issues that needed to be addressed was the cabin layout. This sizes the fuselage which the rest of the aircraft is designed around. In order to determine the most optimal passenger configuration several fuselages were sized for 150 passengers with different seating and aisle configurations. The weight and drag coefficient of each fuselage was calculated and the result of this trade study was that the 6 abreast, single aisle, configuration had the lowest weight and nearly the lowest drag and was therefore chosen for this design.

To begin sizing the wing and engines, a constraint diagram was generated. This illustrates what point performance constraints limit the design. The range capabilities of the Sparrow were determined by constructing the payload-range diagram shown below in Figure 3. The mission analysis tool plays a crucial role in the sizing of the aircraft. Using B737800 parameters, the mission analysis was computed and compared to the actual data. The predicted block fuel was very close to the actual data, as shown in Table 2.

1 Student, Aerospace Engineering, AIAA Student Member.

2 Lockheed Martin Endowed Professor, Aerospace Engineering, AIAA Member.

3 Instructor, Aerospace Engineering. Program Manager, Lockheed Martin Skunk Works, Retired. AIAA Member. 
Table 2: Mission Analysis Validation

\begin{tabular}{|l|l|l|} 
Mission Length & $\begin{array}{l}737 \text { Actual } \\
{[\mathrm{lbs} / \text { seat] }}\end{array}$ & $\begin{array}{l}\text { 737 Predicted } \\
{[\mathrm{lbs} / \text { seat] }}\end{array}$ \\
\hline $500 \mathrm{nmi}$ & 46.6 & 45.4 \\
\hline $1000 \mathrm{nmi}$ & 83.3 & 84.6 \\
\hline
\end{tabular}

In order to optimize the aircraft it was $\mathbf{I}$ important to understand how any change in one of the design variables would effect the ability to fulfill the requirements. As fuel burn was deemed the most important metric in the design of The Sparrow, it was necessary to investigate how small changes in configuration affected the fuel efficiency of the aircraft. Several partial derivatives of fuel burn with respect to design variables were calculated using finite differencing.

From an aerodynamics perspective, increasing aspect ratio yields better range performance. However, wing weight also increases sharply with aspect ratio while maximum lift to drag ratio and cruise lift to drag ratio diverge. This indicates an optimization problem. Aspect ratio was

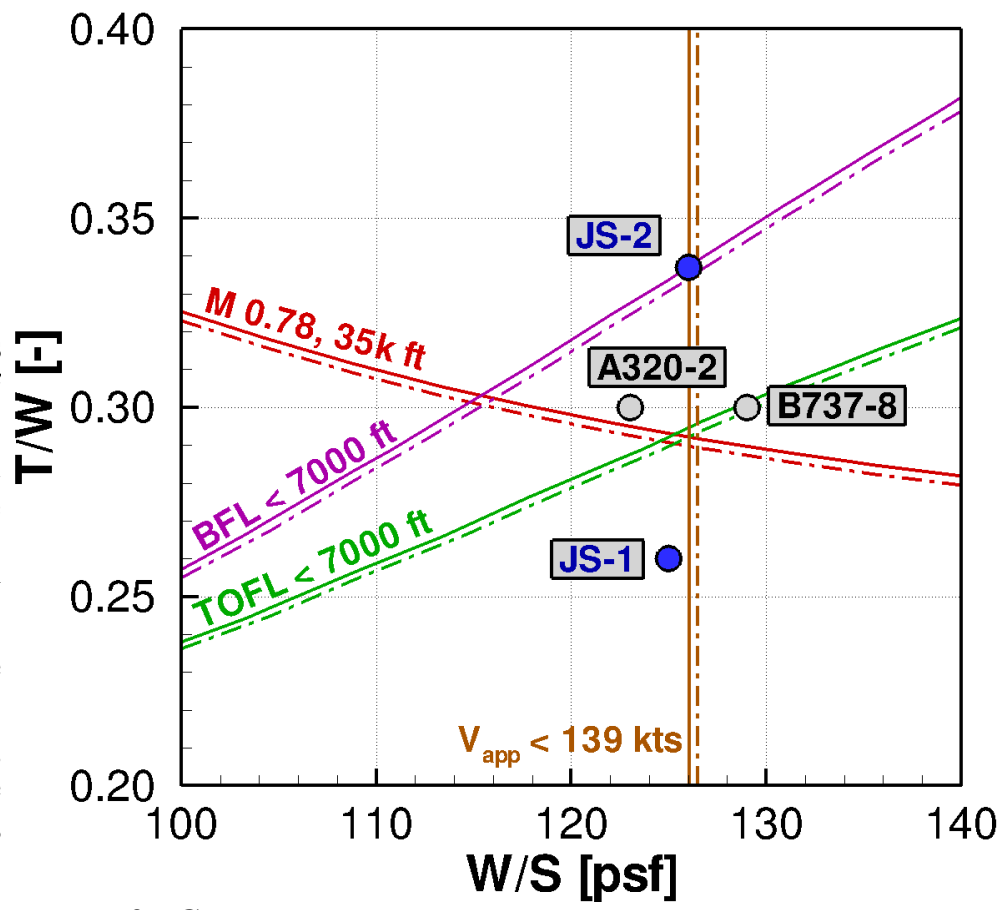

Figure 2: Constraint Diagram was used as an average mission length and the optimum aspect ratio was calculated to be 11 .

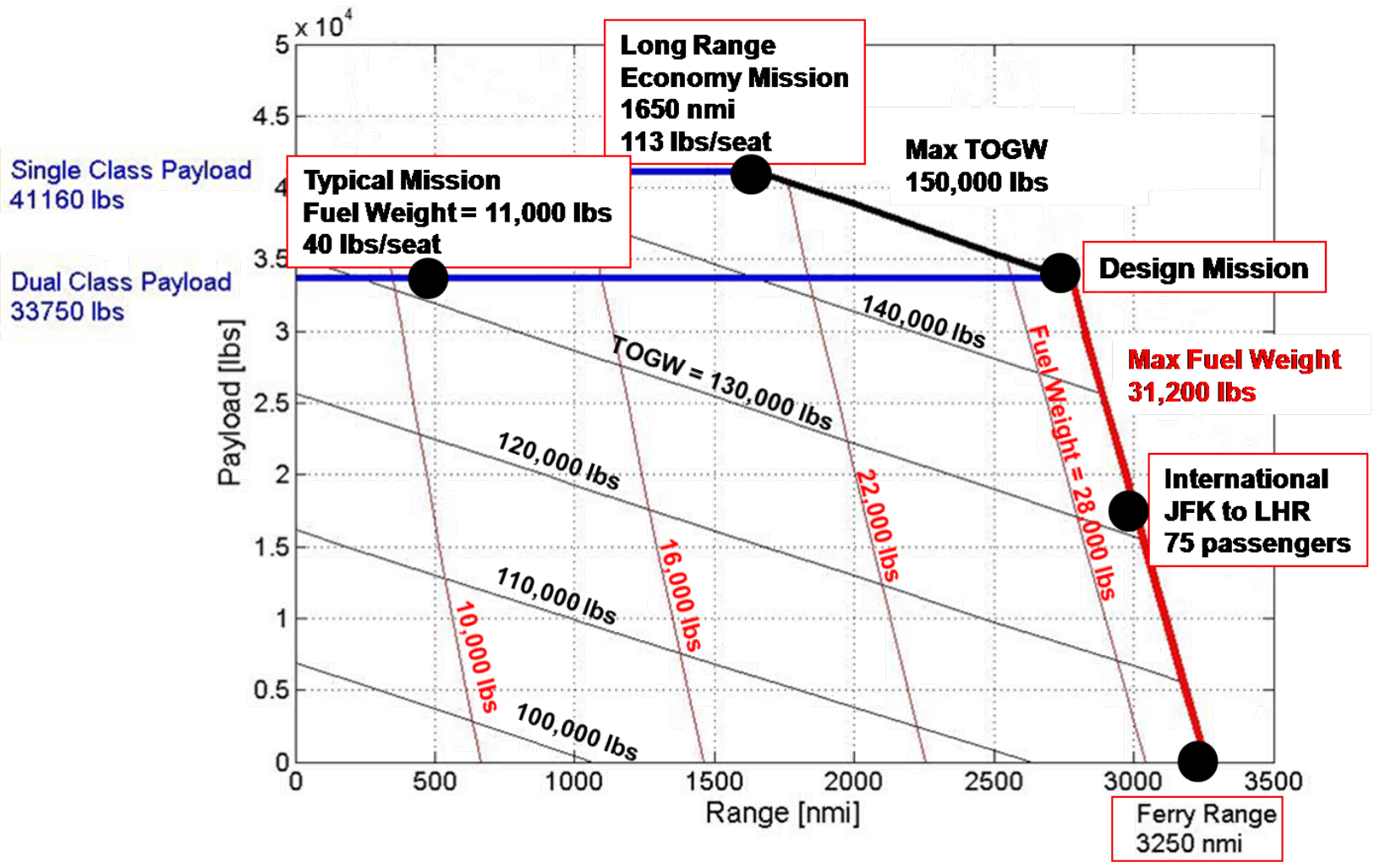

Figure 3: Payload-Range Diagram 
The RFP requires community noise to be $20 \mathrm{~dB}$ below ICAO stage 4. The cumulative noise is the sum of the noise levels from approach, sideline, and flyover, shown graphically in Figure 4.

The ICAO requirements are a good starting point for quantifying aircraft noise, however the observer locations do not represent the entire community surrounding the airport. Using MATLAB to automate the noise simulation process through ANOPP, the noise footprints of the Figure 4: Observer locations for ICAO stage 3 noise evaluation
JS-3 and the B737-400 were generated, as shown in Figure 5.

\section{Aerodynamics}

Aerodynamic twist was implemented to better tailor the wing to an elliptical lift distribution prior to any geometric twist. Figure 6 shows a lift coefficient distribution corresponding to an elliptical lift distribution to produce the required $L$ lift at cruise. The red line shows how the design lift coefficients of the airfoils vary along the span. The numbers correspond to the different airfoils in Figure 7, which displays the airfoils NASA supercritical airfoils selected for the wing. In order to get an arbitrary planform to III. Noise
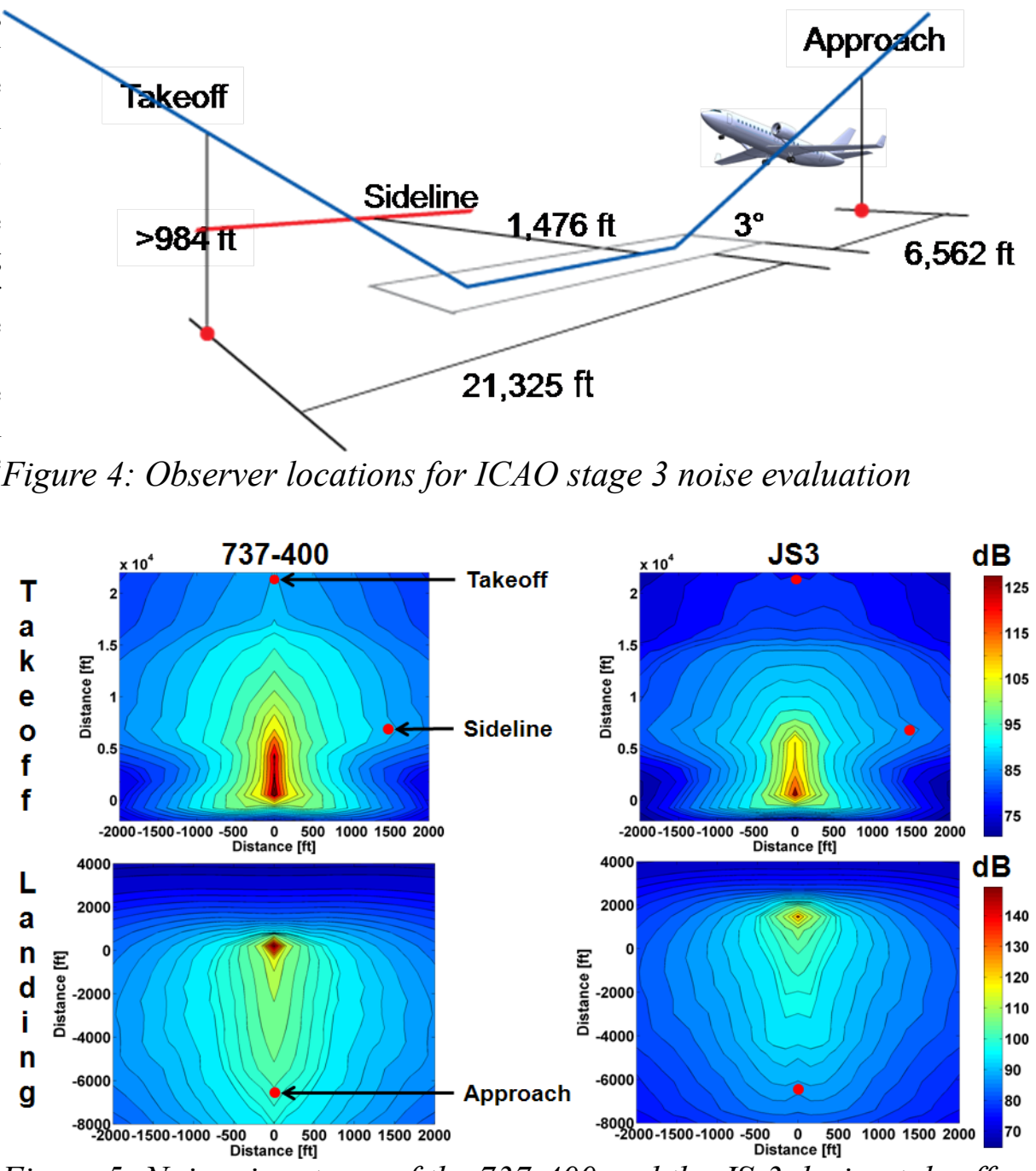
produce an arbitrary lift distribution,Figure 5: Noise signatures of the 737-400 and the JS-3 during takeoff a method was created toand approach

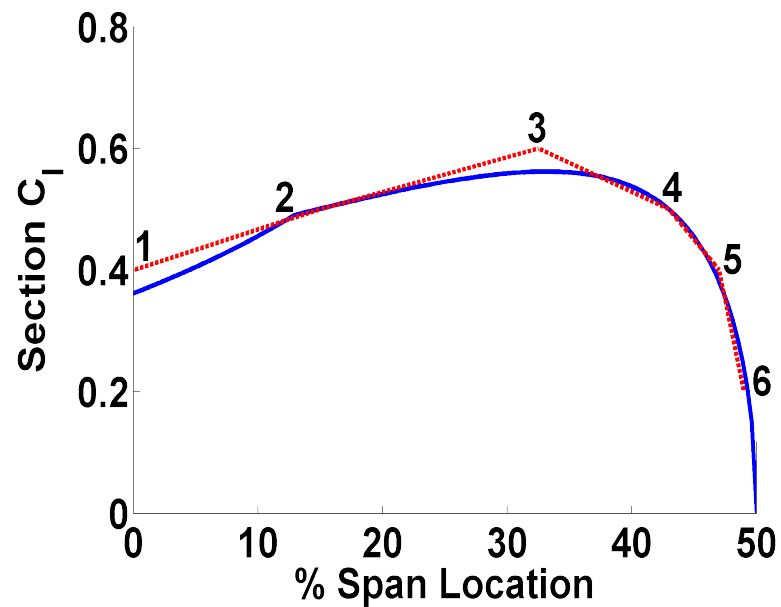

Figure 6: Lift and Airfoil Distributions

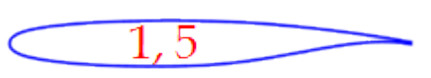

NASA SC(2)-0412

$$
\mathrm{C}_{\mathrm{l}, \mathrm{design}}=0.4
$$

Modified NASA Airfoil

$$
\mathrm{C}_{\mathrm{l}, \mathrm{design}}=0.5
$$

NASA SC(2)-0612

$$
\mathrm{C}_{\mathrm{l}, \mathrm{design}}=0.6
$$

Modified NASA Airfoil

$$
\mathrm{C}_{\mathrm{l}, \mathrm{design}}=0.2
$$

Figure 7: Selected Airfoils 
geometrically twist a given planform to match a desired lift distribution. The twist optimization process involved twisting the wing with a known basis function. The lift distribution was then calculated using the NASA panel code PMARC ${ }^{1}$ automated using MATLAB ${ }^{2}$. This was done for several twist distributions, the resulting lift distributions were superimposed to match the desired lift distribution.

Table 3: Basis Function Buildup

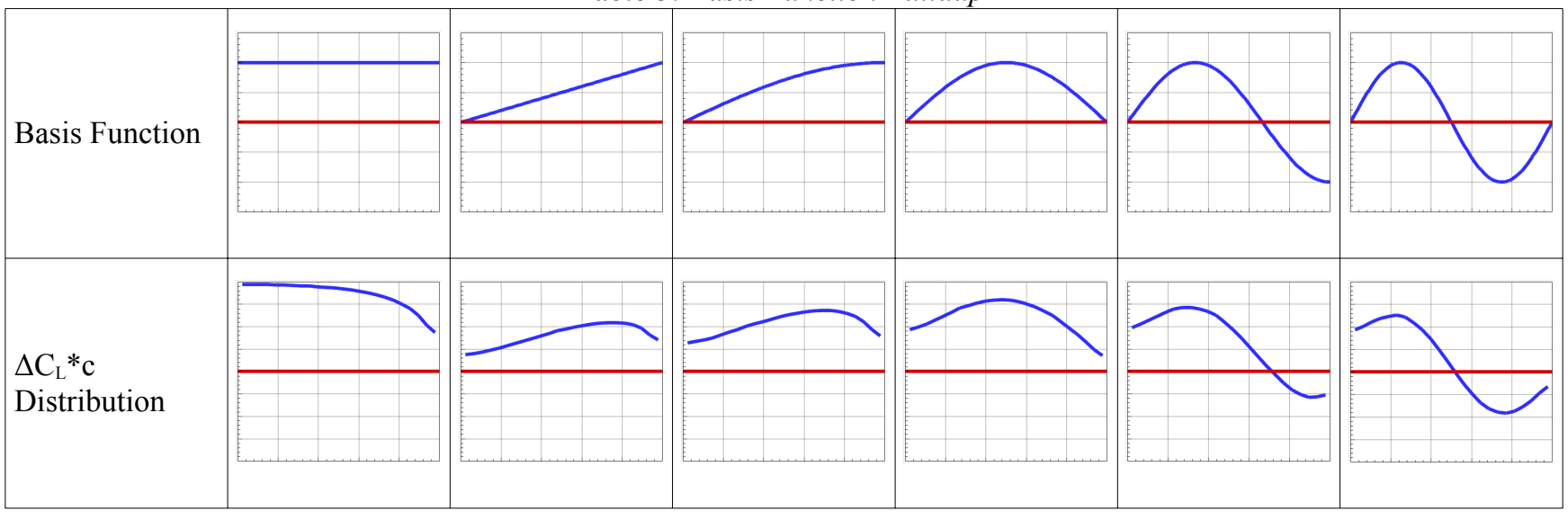

Table 4: Drag Count Buildup

\begin{tabular}{|l|l|l|}
\hline Part & $C_{D .0}$ (Drag Counts) & Percentage \\
\hline Fuselage & 70 & 29 \\
\hline V-Tail & 14 & 6 \\
\hline Horizontal Tail & 17 & 7 \\
\hline Nacelle & 38 & 16 \\
\hline Wing & 73 & 30 \\
\hline Total & 212 & 88 \\
\hline Pressure & 11 & 4 \\
\hline Wave & 20 & 8 \\
\hline Total & 243 & 100 \\
\hline
\end{tabular}
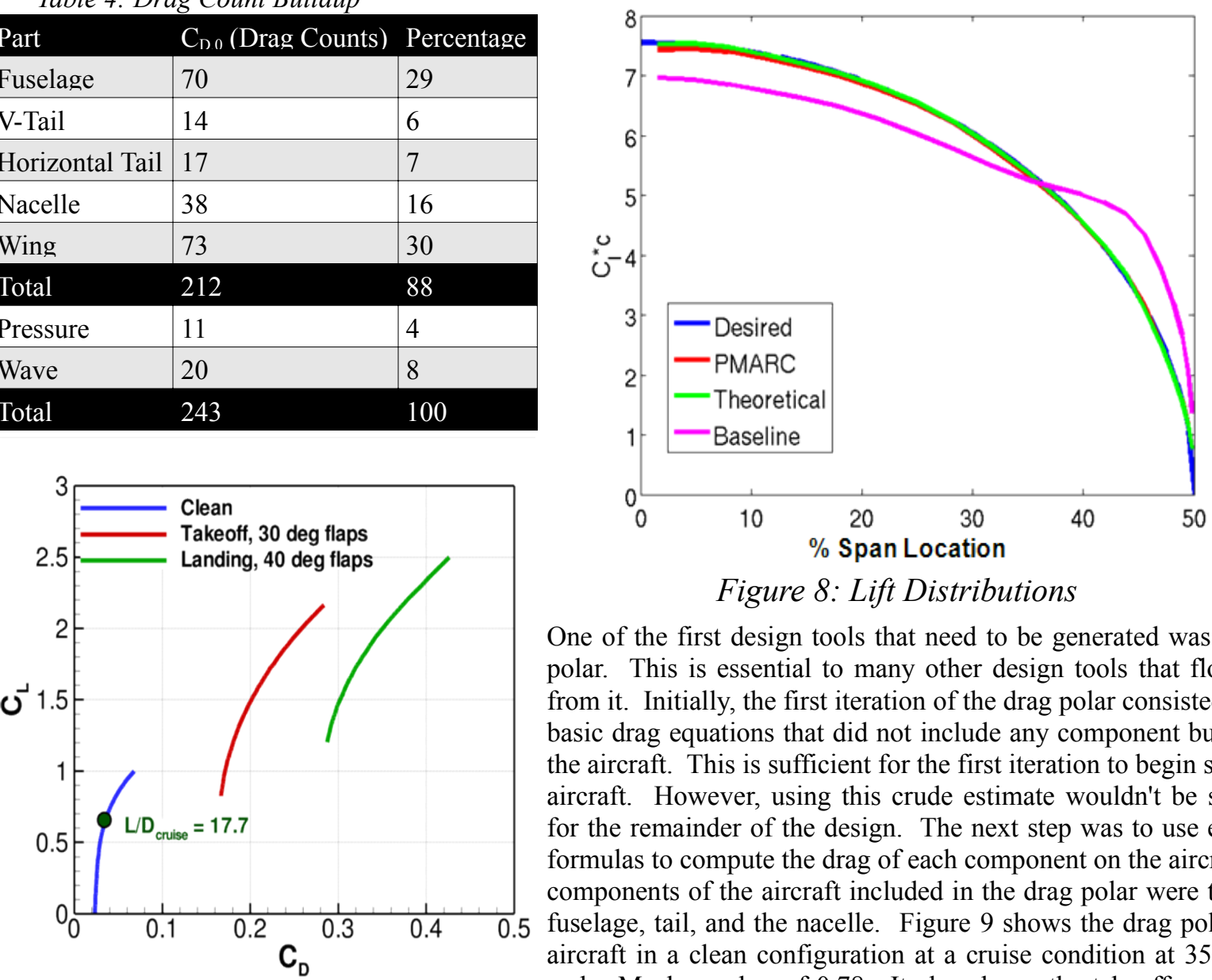

Figure 9: Drag Polars

Figure 8: Lift Distributions

One of the first design tools that need to be generated was the drag polar. This is essential to many other design tools that flow down from it. Initially, the first iteration of the drag polar consisted of very basic drag equations that did not include any component build up of the aircraft. This is sufficient for the first iteration to begin sizing the aircraft. However, using this crude estimate wouldn't be sufficient for the remainder of the design. The next step was to use empirical formulas to compute the drag of each component on the aircraft. The components of the aircraft included in the drag polar were the wing, fuselage, tail, and the nacelle. Figure 9 shows the drag polar of the aircraft in a clean configuration at a cruise condition at 35,000 feet and a Mach number of 0.78. It also shows the takeoff and landing drag polars. 


\section{Propulsion}

Table 5: Propulsion system trade study

\begin{tabular}{|l|c|c|c|c|}
\hline Criteria & \multicolumn{2}{c}{ Value Geared Turbofan } & Advanced Direct Drive Turbofan Unducted Fan \\
\hline $\begin{array}{l}\text { Fuel Burn } \\
\text { (Vs Current) }\end{array}$ & 60 & $\begin{array}{c}0 \\
-12 \%\end{array}$ & $\begin{array}{c}-1 \\
-8 \%\end{array}$ & $\begin{array}{c}2 \\
-25 \%\end{array}$ \\
\hline $\begin{array}{l}\text { Community Noise } \\
\text { (Vs ICAO Stage 4) }\end{array}$ & 16 & $\begin{array}{c}0 \\
-20 \mathrm{~dB}\end{array}$ & $\begin{array}{c}-1 \\
-10 \mathrm{~dB}\end{array}$ & $\begin{array}{c}-5 \\
\mathrm{~dB}\end{array}$ \\
\hline Fleet Productivity & 14 & 0 & 2 & -2 \\
\hline $\begin{array}{l}\text { Maintenance Cost } \\
\text { (Vs Current) }\end{array}$ & 8 & 0 & 2 & -2 \\
\hline Passenger Comfort & 2 & $-10 \%$ & $-15 \%$ & Base \\
\hline Total & 100 & 0 & 0 & -5 \\
\hline
\end{tabular}

Candidate propulsion concepts are analyzed below with a graphical representation in Table 5. Quantitative values are included wherever possible to justify relative values assigned in the trade study (values range from +5 to $-5)$.

Based on the pre-established criteria, the baseline GTF wins out over the UDF and the LEAP56. The performance of Pratt \& Whitney's PW1000G during the flight profile is shown in Figure 10. Even though the geared turbofan appears to be a very safe bet for a 2018 entry to service date, if the program does not produce the excepted success, a direct drive turbofan can easily be installed in its place because the size and performance of the turbofans are not radically different.

With larger diameter engines, this poses a problem with ground clearance. A couple ways to tackle this problems

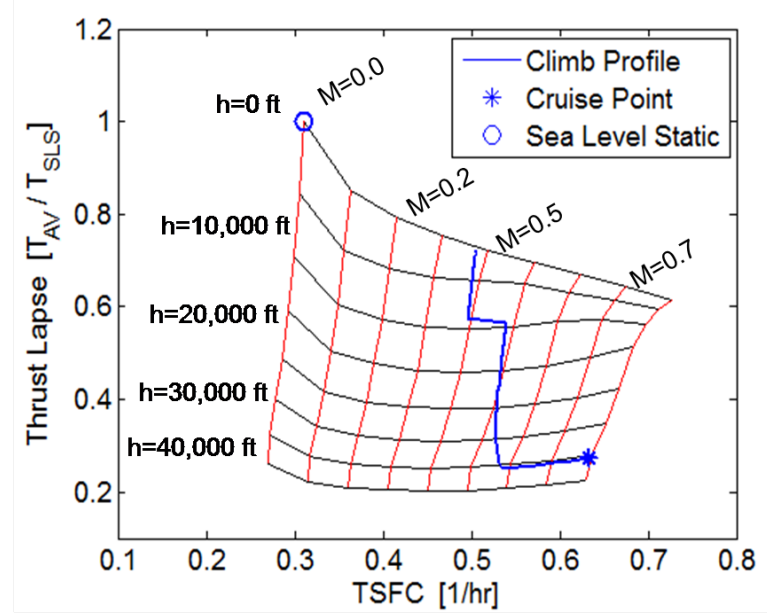
would be extend the landing gear and/or increase the dihedralFigure 10: Geared Turbofan performance overview

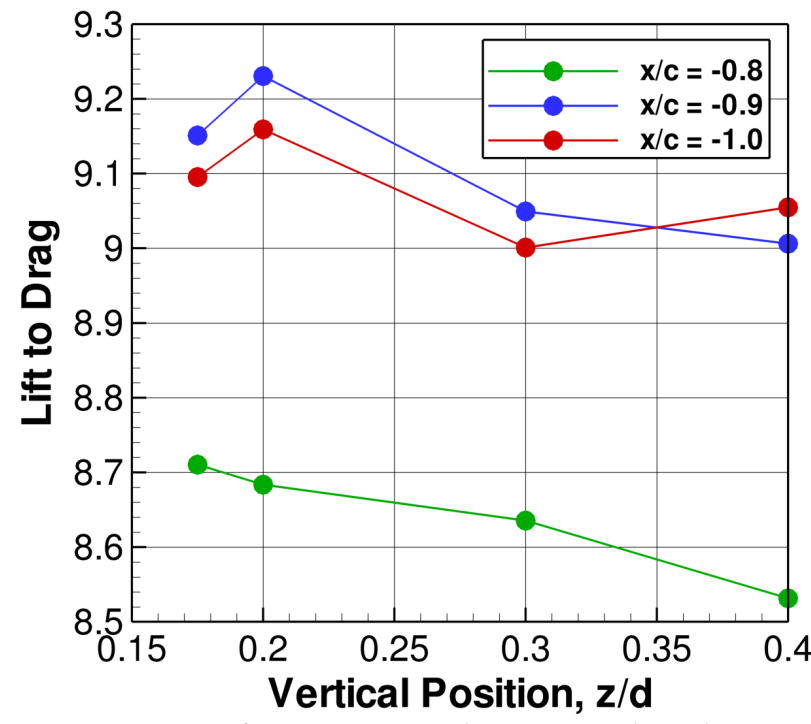

Figure 11: Lift to Drag with varying height

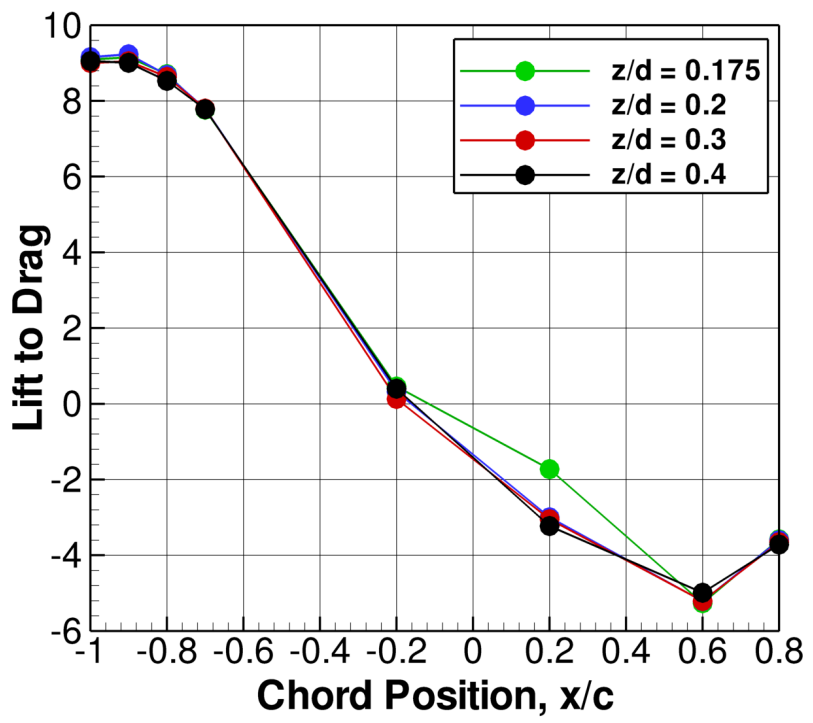

Figure 12: Lift to Drag with varying chord

5

American Institute of Aeronautics and Astronautics 
of the wing. Unfortunately, both will induce large unfavorable weight penalties. One of the most promising configurations is to place the engine over the wing. Over the wing nacelle (OWN) installations may prove increasingly necessary for future commercial aircraft as nacelle diameters continue to increase and noise regulations become stricter. Placing the nacelles over the wing will result in a noise reduction from the shielding of the jet exhaust by the wing. Although promising, this type of configuration has not been utilized very much in the past. One major reason is the unfavorable aerodynamic interference it creates at transonic cruise conditions. The presence of a nacelle and pylon disturbs the wing's upper surface pressure distribution which leads to excessive interference, badly misplaced shocks, and large flow separations. Figure 12 shows how lift to drag changes with chord positions for various heights. Figure 11 shows how lift to drag changes with nacelle height for various chords positions. The trend appears to be that as the nacelles move further aft, lift to drag diminishes. From Figure 12 the best lift to drag occurs between a chord position of -1.00 and -0.80 . Looking at Figure 11, the best lift to drag position occurs at -0.9

\section{Structures}

One of the goals of performing a bending analysis on the JS-3 wing was to extract wing geometry from the bending moment, which was then used to determine the structural volume for the given loading conditions. Wing weight was then determined simply by specifying a material density. The wing was analyzed as a cantilever beam with a semi-monocoque structure. This structure was represented by a front and rear spar, with top and bottom skins assumed to have a minimum gauge thickness of 0.065 inches and a constant thickness to chord ratio of $12 \%$ along the span. This assumed wing structure accounts for taper in the wing, but does not account for wing sweep or twist. The forces included in this analysis were bending moments caused by an elliptical lift distribution, a linearly tapering wing weight model, fuel weight, all of which are distributed loads, and the engine,

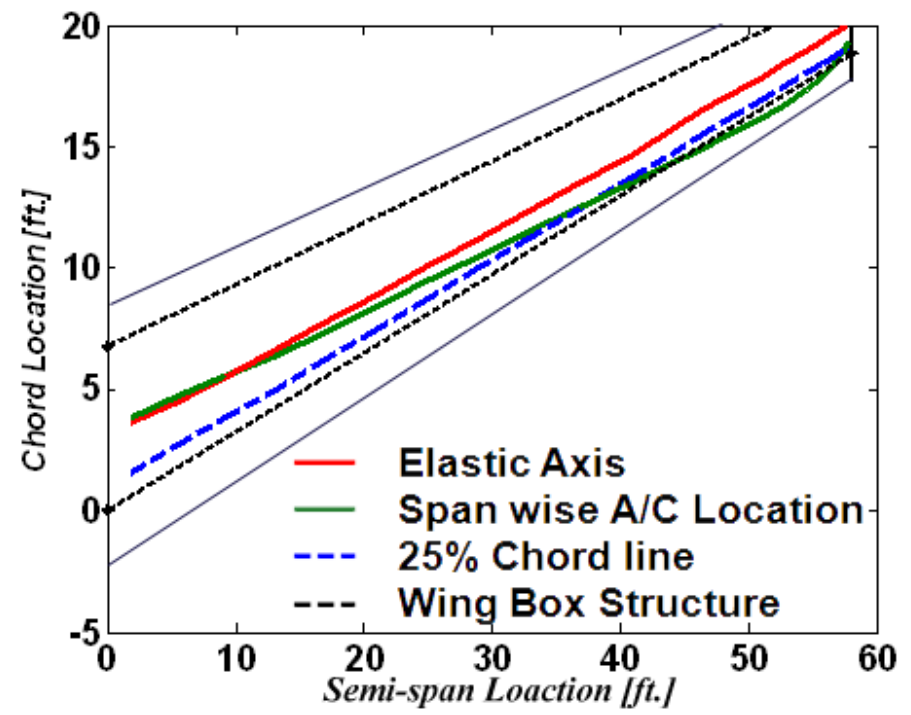

Figure 13: Elastic axis and aerodynamic center locations along span which is treated as a point load.

Preliminary aeroelastic analysis was performed on the planform design to determine the implications it may have on the dynamic stability of the structure in-flight. Aeroelastic effects such as aileron reversal, flutter, aero-servoelasticity, and dynamic divergence have complicated response modes and require powerful calculation and simulation tools to accurately model.

One of the key concepts of aeroelasticity is the location of the wing aerodynamic center in relation to the elastic axis of the wing. Ideally, the wing should be designed so the aerodynamic center is located at or behind the elastic axis of the local chord. Any loads applied at the location
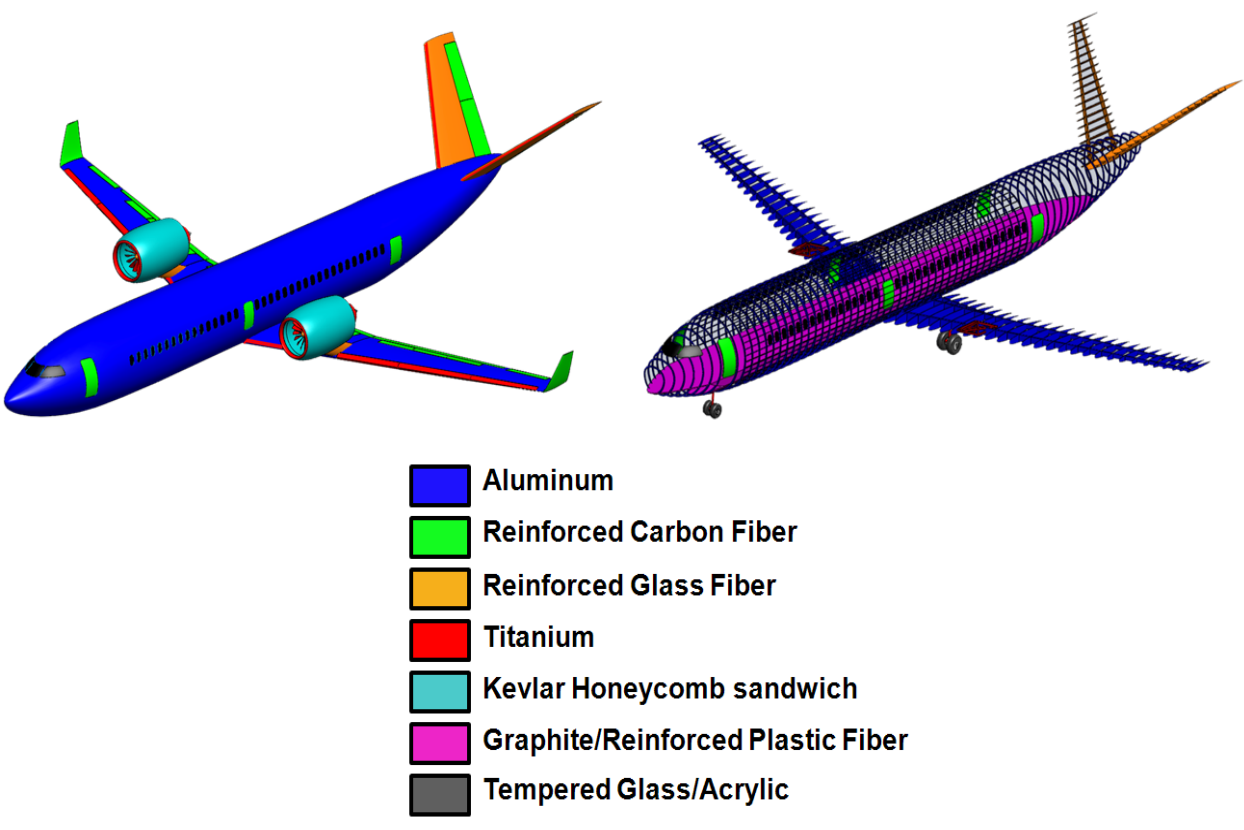

Figure 14: Internal and external materials utilization on JS-3 Sparrow 
of the elastic axis will result in a pure bending response, limiting the stresses seen on the wing.

It was important to construct the Sparrow out of light weight, high strength materials, that would perfom well throughout the lifespan of the aircraft, and not be environmentally damaging during the manufacture or disposal of the material at is end-of-life cycle. Some of the materials featured on The Sparrow are advanced, light weight, high strength aluminum alloys and advanced composite construction which include the utilization of carbon, glass, and Kevlar fibers.

Recently composites have been playing a larger roll in aircraft construction. Their light weight and high tensile characteristics make it the ideal aircraft construction material. Newer aircraft such as the Boeing 787 feature a virtually all composite construction and seem to be leading an ever increasing trend to all composite construction. The merits of all composite construction were investigated for use on the Sparrow, and it was determined that the high cost of manufacture and repair, the unknown mechanical properties of composites, and the environmental impact of the disposal of hazardous construction materials such as resins and epoxies were too high of a risk to be implemented into the construction of the entire aircraft. This led to the investigation of more advanced applications of traditional construction materials. These materials include new, high strength, lightweight lithium aluminum and titanium alloys whose mechanical properties are well known, they are easily recyclable, and are less expensive to manufacture than composites. Figure 14 shows the internal and external implementation of materials on the Sparrow.

Typically engine pylon mounts our constructed out of titanium or steel alloys in order to withstand the large loads generated from the engine. Ti 6-4 titanium alloy was selected as the construction material for the JS-3 pylon due to its exceptional tensile strength $(150,000 \mathrm{psi})$, high strength to weight, resistance to fatigue, and ability to maintain structural strength and integrity under high temperatures inherit with engine operation. Because the engine pylon structure is subjected to large inertial and propulsive loads, it is necessary to design the pylon structure to withstand extreme loading cases. In order to ensure the Sparrow pylon design is able to withstand these extreme loads while maintaining structural integrity, some preliminary finite element analysis (FEA) was done on the pylon using Abaqus CAE software ${ }^{3}$. This allowed the magnitudes and locations of maximum stress concentration to be determined. The FEA analysis done on the pylon involved applying propulsive, side, and weight forces with sufficient load factors at the proposed engine-pylon mounting points. The design load factors used in this analysis are summarized below in Table 6 from Niu, which cites the inertial load factors and conditions for the preliminary sizing of commercial transports.

Table 6: Load factors used in pylon FEA analysis

\begin{tabular}{|l|l|}
\hline Condition & Ultimate Load Factors \\
\hline Vertical & $6.5+1.5 T(\mathrm{C})$ \\
\hline Thrust & $3.0 T(\max )+3.0$ vertical \\
\hline Side & \pm 3.0 \\
\hline
\end{tabular}

These load factors were applied in the FEA analysis on the pylon and determined the ultimate stresses the pylon would experience. In addition, this analysis shows how the pylon deforms and what failure criteria the structure undergoes. The results of this analysis are seen in Figure 15 which shows the Von Mises stresses (psf) and deformation of the structure with a deformation scale factor of twenty. This yields a maximum Von Mises stress in the members

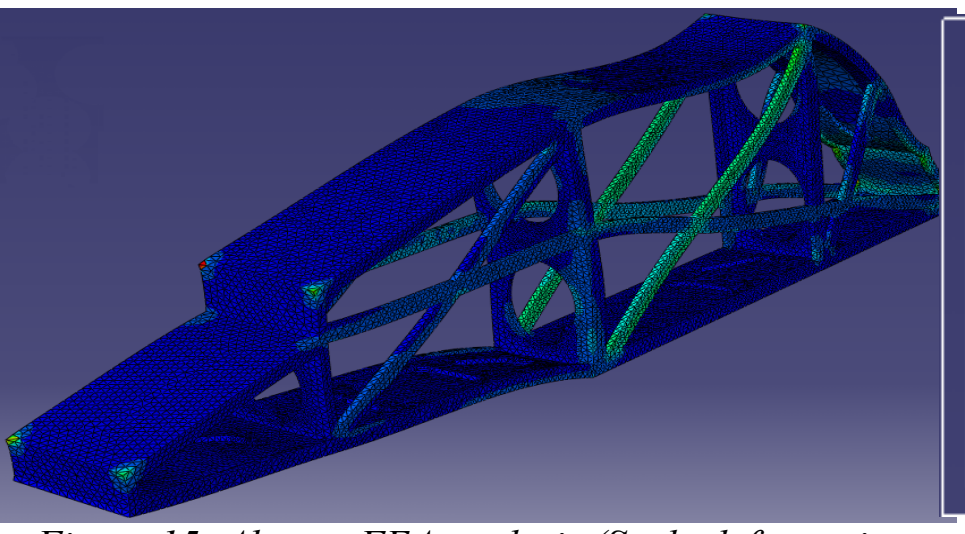

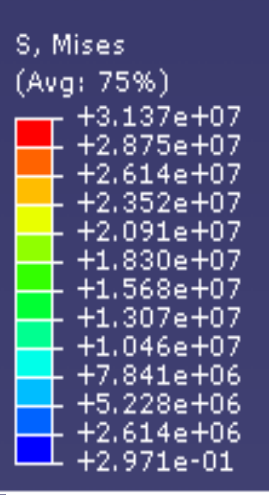

Figure 15: Abaqus FEA analysis (Scale deformation factor $=20.0$ ) of $127,000 \mathrm{psi}$, which is within the yield stress of 150,000 psi for Ti 6-4 titanium alloy. It can also be seen that the main failure mode for the structure is the buckling of the stiffner spars and bulkheads in the aft section of the pylon. 


\section{Mass Properties}

The JS-3 component weights breakdown using the previously developed hybrid wing weight model is seen in Figure 16. This yielded an empty weight of 78,600 pounds and a takeoff gross weight of 143,800 pounds, which includes a 31,200 pound fuel weight and a 34,000 pound payload weight. In Figure 16, the red bars indicate the component weight before the advanced materials previously mentioned were implemented. Because structural components such as the wing, and fuselage comprise a large percentage of the total empty weight, it was importance to implement lightweight alloys to these components where their lightweight properties would have the greatest effect in reducing empty weight. The blue bars indicate the component weight after advanced materials were implemented. The introduction of these materials resulted in an empty weight reduction from 84,500 pounds to 78,600 pounds, or a $6 \%$ reduction in structural weight.

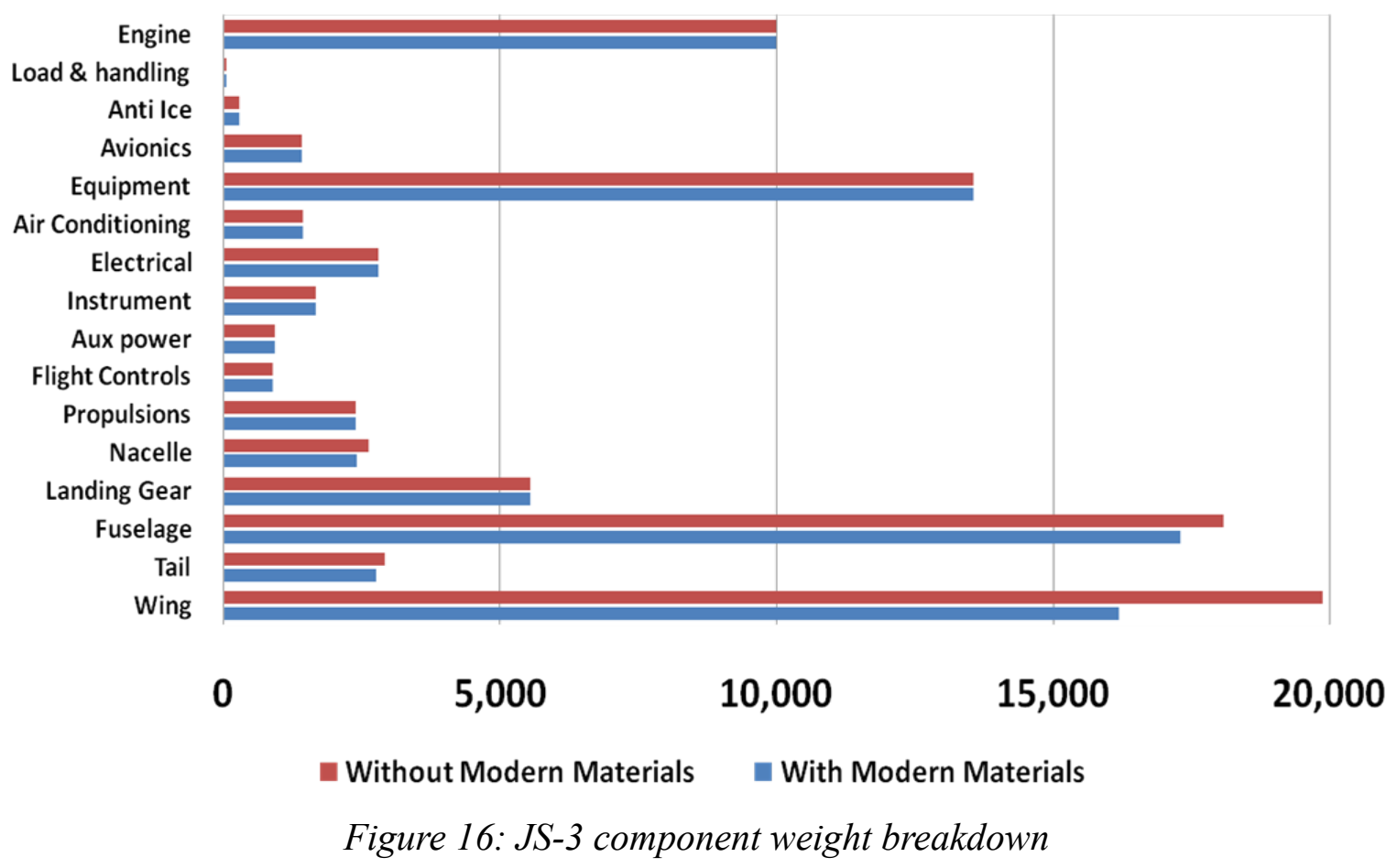

\section{Stability and Controls}

It is required by the FAA that the Sparrow be stable in all axes, defined in FAR 25.173 and 25.177, and this was of primary concern when designing the aircraft's control system. Several control surface configurations were considered during preliminary design and investigated based on the figures of merit determined in the beginning of the design process. The V-tail was selected as the configuration best suited for this aircraft. In addition to reducing total tail area, resulting in reduced drag and weight, it removes the horizontal tail from the path of the engine exhaust which would cause increased scrub drag and possibly fatigue the material or reduce control surface effectiveness.

The vortex lattice method $\mathrm{AVL}^{4}$, created by Mark Drela and Harold Youngren, was used to calculate the static stability of the aircraft for several tail sizes to produce the tail sizing plot shown in Figure 17 by varying

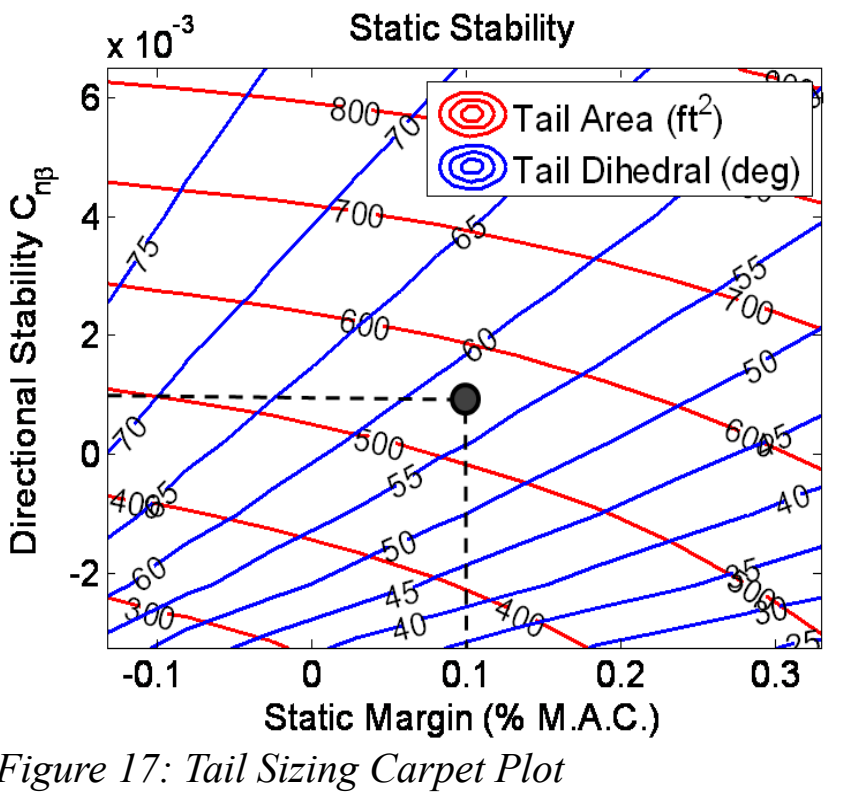


tail area and dihedral angle at constant aspect and taper ratios. Desired static stability values for this class of aircraft included a longitudinal static margin of $10 \%$ and a minimum yawing moment coefficient, $\mathrm{C}_{\mathrm{n} \beta}$, of at least 0.001 per degree as recommended by Roskam ${ }^{5}$. This tail sizing approach resulted in a tail area of $550 \mathrm{ft}^{2}$ with a dihedral angle of 57 degrees.

In the trim diagram in Figure 18 it can be seen that the cruise $\mathrm{Cl}$ of 0.58 is achieved at an angle of attack of 3 degrees with -2 degrees of elevator deflection assuming $U$ -3 degrees of tail incidence.

The dynamic stability characteristics of The Sparrow were calculated using AVL which provides the frequency and damping ratio of all dynamic modes of the aircraft. These values along with the associated flying qualities as defined by MIL-F-8785C are presented in Table 7. It should be noted the the level 1 requirement for the spiral mode is a doubling time of greater than 20 seconds which is an unstable condition.Figure 18: Cruise Trim Diagram, 0.78 Mach, 35,000 ft. The Sparrow is stable in all modes and therefore doubling time has no physical significance, as a result the time to halve amplitude is presented instead.

\section{Cruise Trim Diagram}

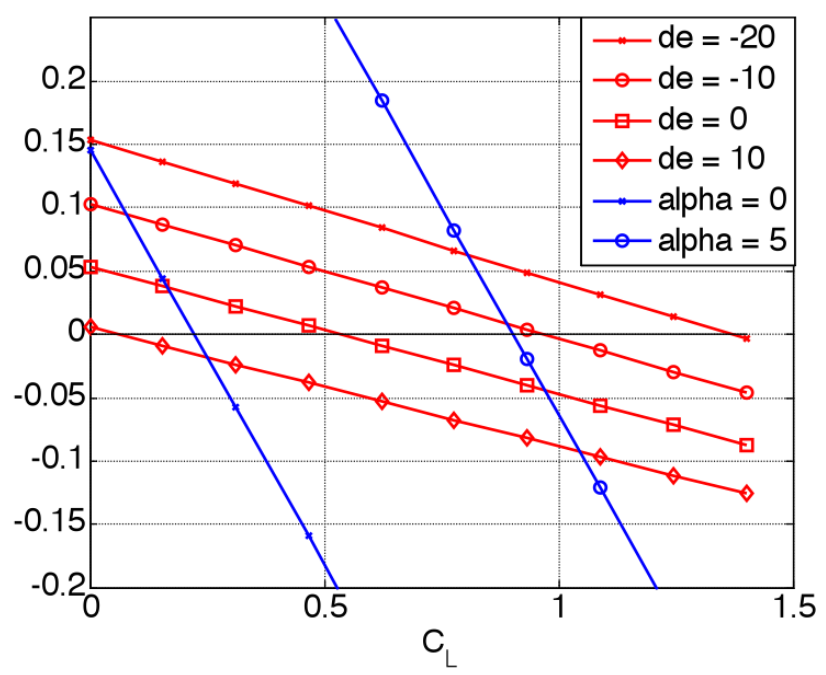

Table 7: Dynamic Stability and Flying Qualities

\begin{tabular}{|c|c|c|c|c|c|c|c|}
\hline Mode & $\begin{array}{l}\text { Flight } \\
\text { Phase }\end{array}$ & $\begin{array}{c}\text { Natural Frequency } \\
\omega_{\mathrm{n}}(\mathrm{rad} / \mathrm{sec})\end{array}$ & $\begin{array}{l}\text { Damping } \\
\text { Ratio } \xi\end{array}$ & $\begin{array}{c}\text { Time } \\
\text { Constant } \tau(\mathrm{s})\end{array}$ & $\begin{array}{c}\text { Time to Half } \\
\text { Amplitude } t_{1 / 2}(s)\end{array}$ & $\begin{array}{c}\text { MIL-F 8785C } \\
\text { Requirement for Level } 1\end{array}$ & $\begin{array}{l}\text { Flying } \\
\text { Quality }\end{array}$ \\
\hline \multirow[t]{2}{*}{ Phugoid } & Cruise & 0.04 & 0.07 & -- & -- & \multirow[t]{2}{*}{$\xi>0.04$} & Level 1 \\
\hline & Approach & 0.09 & 0.04 & -- & -- & & Level 1 \\
\hline \multirow{2}{*}{$\begin{array}{l}\text { Short } \\
\text { Period }\end{array}$} & Cruise & 11.4 & 0.56 & -- & -- & $0.30<\xi<2.0$ & Level 1 \\
\hline & Approach & 3.01 & 0.53 & -- & -- & $0.35<\xi<1.2$ & Level 1 \\
\hline \multirow{2}{*}{$\begin{array}{l}\text { Dutch } \\
\text { Roll }\end{array}$} & Cruise & 3.65 & 0.81 & -- & -- & $\xi>0.08, \omega_{n}>0.40$ & Level 1 \\
\hline & Approach & 2.24 & 0.47 & -- & -- & $\xi>0.08, \omega_{n}>1.0$ & Level 1 \\
\hline \multirow[t]{2}{*}{ Roll } & Cruise & -- & -- & 0.02 & -- & \multirow[t]{2}{*}{$\tau<1.4$} & Level 1 \\
\hline & Approach & -- & -- & 0.09 & -- & & Level 1 \\
\hline \multirow[t]{2}{*}{ Spiral } & Cruise & -- & -- & -- & 27.77 & \multirow[t]{2}{*}{$\mathrm{t}_{2}>20 \mathrm{~s}$} & Level 1 \\
\hline & Approach & -- & -- & -- & 15.97 & & Level 1 \\
\hline
\end{tabular}

A simulator model of The Sparrow, shown in Figure 19, was constructed using X-Plane ${ }^{6}$ to further investigate the characteristics of the aircraft as well as validate the design and analysis that had been performed. X-Plane estimates the aerodynamic forces on the aircraft using blade element theory based on the geometry of the aircraft along with several corrections for compressibility, 3-D effects, etc. This results in a model which very closely represents the performance of the aircraft while also being sensitive to small changes in geometry or configuration.

This simulator model was flown by several engineers as well as pilots, both private and commercial, with no reported deficiencies in either the stability or controllability of the aircraft. This serves as a validation of both the design as well as the stability and aerodynamic analyses that were performed.

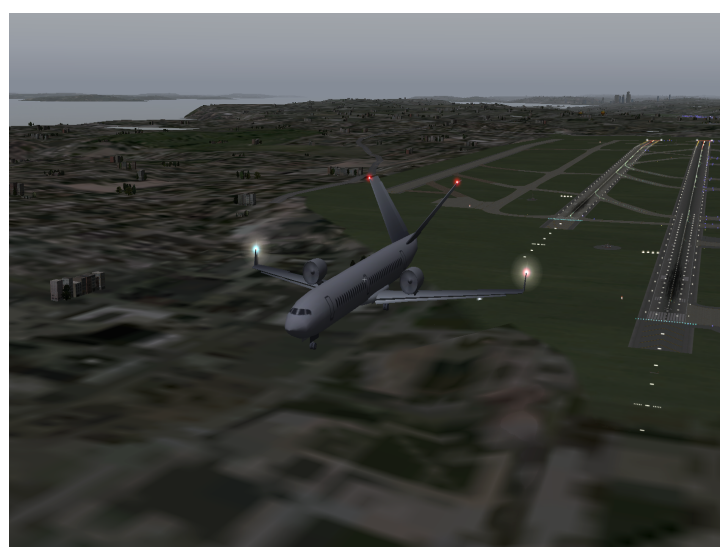

Figure 19: X-Plane Flight Simulator Model 


\section{Conclusion}

The compliance of The Sparrow with the main RFP requirements is shown in Table 8.

Table 8: RFP Compliance

\begin{tabular}{|l|c|c|c|}
\hline Metric & Requirement & JS -2 & Status \\
\hline Fuel Burn & $<41 \mathrm{lbs} / \mathrm{seat}$ & $40 \mathrm{lbs} / \mathrm{seat}$ & $\sqrt{ }$ \\
\hline Noise vs. Chapter 4 & $-20 \mathrm{db}$ & $-21 \mathrm{db}$ & $\sqrt{ }$ \\
\hline Operating Cost & $>8 \%$ decrease & $8.5 \%$ decrease & $\sqrt{ }$ \\
\hline Flyaway Cost & Maintain & Decreased & $\sqrt{ }$ \\
\hline Passenger Comfort & Maintain & Maintained & $\sqrt{ }$ \\
\hline Range (Dual Class) & $2800 \mathrm{nmi}$ & $2800 \mathrm{nmi}$ & $\sqrt{ }$ \\
\hline Cruise Speed & $>0.78 \mathrm{Mach}$ & $>0.8$ Capable & $\sqrt{ }$ \\
\hline Takeoff Field Length & $<7000 \mathrm{ft}$ & $\mathrm{BFL}<7000 \mathrm{ft}$ & $\sqrt{ }$ \\
\hline
\end{tabular}

The Sparrow meets or exceeds all of the requirements, and is an optimal solution to this RFP. The Sparrow's unique configuration and technological improvements over current 150 passenger class airliners are the reasons it will perform well in this competitive industry. The Sparrow features high-bypass geared turbofan engines which provide improvements in both fuel efficiency and noise reduction. Advanced structural and aerodynamic design and analysis coupled with a noise shielding configuration result in a next generation commercial aircraft which is capable of operating within current infrastructure. The Jackson West Sparrow JS-3 is, indubitably, the aircraft of tomorrow. 
1 Panel Method Ames Research Center (PMARC), Software Package, Vers. 14. NASA Ames, Moffett Field, CA, 1999.

2 MATLAB, Software Package, Vers. 7.6.0.324 (R2008a). The Mathworks Inc., Natick, MA, 2008.

3 ABAQUS CAE. Computer software. Vers. 6.7.3. D S Simulia Dassault Systèmes, 2007.

4 Athena Vortex Lattice. Computer software. Cambridge, Massachusetts, United States: Mark Drela and Harold Youngren, 2006.

5 Roskam, Jan. Airplane Design Part II: Preliminary Configuration Design and Integration of the Propulsion System. Ottawa: Roskam Aviation and Engineering Corporation, 1989.

6 X-Plane. Computer software. Columbia, South Carolina, United States: Laminar Research, 2009. 